\title{
Relaxivity of Gd-based contrast agents on X nuclei with long intrinsic relaxation times in aqueous solutions
}

\author{
Ruud B. van Heeswijk ${ }^{\mathrm{a}}$, Sabrina Laus ${ }^{\mathrm{b}}$, Florence D. Morgenthaler ${ }^{\mathrm{a}}$, Rolf Gruetter ${ }^{\mathrm{a}, \mathrm{b}, \mathrm{c}, *}$ \\ ${ }^{\mathrm{a}}$ Laboratory for Functional and Metabolic Imaging, Ecole Polytechnique Fédérale de Lausanne, CH-1015 Lausanne, Switzerland \\ ${ }^{\mathrm{b}}$ Department of Radiology, University of Geneva, CH-1210 Geneva, Switzerland \\ ${ }^{\mathrm{c}}$ Department of Radiology, University of Lausanne, CH-1015 Lausanne, Switzerland \\ Accepted 11 January 2007
}

\begin{abstract}
The relaxivity of commercially available gadolinium (Gd)-based contrast agents was studied for X-nuclei resonances with long intrinsic relaxation times ranging from $6 \mathrm{~s}$ to several hundred seconds. Omniscan in pure ${ }^{13} \mathrm{C}$ formic acid had a relaxivity of $2.9 \mathrm{mM} \mathrm{m}^{-1} \mathrm{~s}^{-1}$, whereas its relaxivity on glutamate $\mathrm{C} 1$ and $\mathrm{C} 5$ in aqueous solution was $\sim 0.5 \mathrm{mM}^{-1} \mathrm{~s}^{-1}$. Both relaxivities allow the preparation of solutions with a predetermined short $T_{1}$ and suggest that in vitro substantial sensitivity gains in their measurement can be achieved.

${ }^{6} \mathrm{Li}$ has a long intrinsic relaxation time, on the order of several minutes, which was strongly affected by the contrast agents. Relaxivity ranged from $\sim 0.1 \mathrm{mM}^{-1} \mathrm{~s}^{-1}$ for Omniscan to 0.3 for Magnevist, whereas the relaxivity of Gd-DOTP was at $11 \mathrm{mM}^{-1} \mathrm{~s}^{-1}$, which is two orders of magnitude higher. Overall, these experiments suggest that the presence of 0.1 - to $10-\mu \mathrm{M}$ contrast agents should be detectable, provided sufficient sensitivity is available, such as that afforded by hyperpolarization, recently introduced to in vivo imaging.

(C) 2007 Elsevier Inc. All rights reserved.
\end{abstract}

Keywords: Gadolinium complexes; Carbon-13; Lithium-6; Relaxivity; Contrast agents

\section{Introduction}

The measurement of cerebral metabolism using ${ }^{13} \mathrm{C}$ $\mathrm{NMR}$ in conjunction with administration of ${ }^{13} \mathrm{C}$-labeled precursor substrate is a powerful tool that allows insight into many metabolic processes in vivo, ranging from energy metabolism to neuroglial compartmentation [1,2]. Assessment of these metabolic reactions depends on the measurement of label incorporation into multiple positions in amino acids such as glutamate [3]. Glutamate $\left(\mathrm{C}_{5} \mathrm{H}_{9} \mathrm{NO}_{4}\right)$ consists of three central carbons flanked by carboxyl groups [4], the labeling of which can provide additional insight into neuroglial compartmentation. The ${ }^{13} \mathrm{C}$ nuclei of these carboxyl groups have relaxation times on the order of $10 \mathrm{~s}$, resulting in poor sensitivity for most NMR experiments. Standard approaches to signal enhancement, such as polarization transfer [5] or NOE generation [6], are not available for such carboxyl resonances due to their long

* Corresponding author. Laboratory for Functional and Metabolic Imaging (LIFMET), EPFL-SB-IPMC-LIFMET, Station 6, Ecole Polytechnique Fédérale de Lausanne (EPFL), CH-1015 Lausanne, Switzerland. Tel.: +41216934467; fax: +41216937960.

E-mail address: rolf.gruetter@epfl.ch (R. Gruetter). intrinsic $T_{1}$ (on the order of $10 \mathrm{~s}$ ) and lack of significant coupling to neighboring protons, leaving a shortening of the $T_{1}$ as the only option to improve sensitivity.

Gadolinium (Gd)-based contrast agents are widely used in magnetic resonance imaging to generate contrast by lowering the spin-lattice relaxation time of water protons $[7,8]$. Applications of these contrast agents range from the detection of multiple sclerosis [9] to the visualization of brain tumors [10] and tracking of individual cells in vivo [11]. However, the effect of contrast agents on the relaxation rate of X nuclei is less well known; in fact, we are only aware of a few studies $[4,12]$ none of which reported relaxivity as such.

In the aforementioned ${ }^{13} \mathrm{C}$ NMR studies, formic acid $(\mathrm{HCOOH})$, in essence a free carboxyl group, is frequently used to generate a reference signal with which the power levels of various NMR pulse sequences can be conveniently calibrated and adjusted to experimental conditions such as coil loading [13]. However, the $T_{1}$ relaxation time of formic acid is on the order of $6 \mathrm{~s}$. Consequently, this calibration step requires a substantial effort in time [14].

To demonstrate that Gd-based contrast agents can also be used to predictively shorten the relaxation time of other nuclei, we further extended the scope of the study to ${ }^{6} \mathrm{Li}$, a 
A

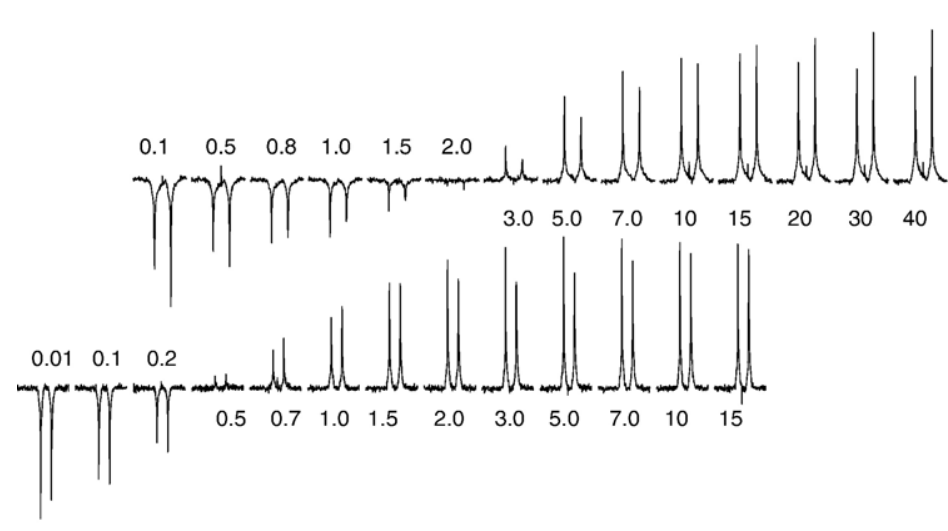

B

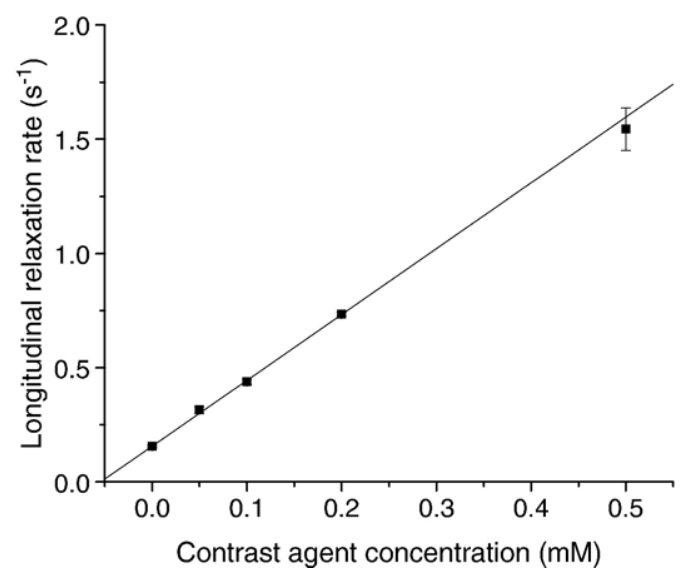

Fig. 1. Effect of Omniscan on formic acid ${ }^{13} \mathrm{C} T_{1}$. (A) Series of ${ }^{13} \mathrm{C}$ spectra of formic acid in the presence of $0.05 \mathrm{mM}$ (upper panel) and $0.5 \mathrm{mM}$ (lower panel) of the contrast agent Omniscan. The signal is a doublet since no decoupling was used. Inversion times ô (s) are indicated for each trace. The inversion null can be seen at 2.0 and $0.5 \mathrm{~s}$, respectively. (B) Linear fit of the relaxation rate $R_{1}$ (s) versus the Omniscan concentration [CA] (mM) to determine the relaxivity. Error bars represent the standard deviation of the $T_{1}$, and fits are too small to be visible for the lower concentrations.

spin-1 with a very small quadrupolar moment, whose intrinsic longitudinal relaxation has been reported as $170 \mathrm{~s}$ in $\mathrm{H}_{2} \mathrm{O}$ [15] and $1040 \mathrm{~s}$ in $\mathrm{D}_{2} \mathrm{O}$ [16]. Lithium is used to treat episodes of mania and depression and to prevent their recurrence [17]. Since ${ }^{6} \mathrm{Li}$ is positively charged, contrast agents with different charges were hypothesized to have a profoundly different effect on $T_{1}$ relaxation. Therefore, the aim of this feasibility study was to characterize the relaxivity of commercially available contrast agents in order to shorten long $T_{1}$ relaxation times of $\mathrm{X}$ nuclei in a predictive manner. Given that, unlike water, most compounds discussed above carry one or more charges at neutral $\mathrm{pH}$ and are thus likely subject to different interactions with contrast agents (which also differ in charge), a secondary aim of this study was to investigate several different contrast agents.

\section{Materials and methods}

Unless stated otherwise, all chemicals of analytical grade were purchased from Sigma-Aldrich (St. Louis, $\mathrm{MO})$ and used without further purification. Omniscan ([Gd(DTPA-BMA) $\left.\left(\mathrm{H}_{2} \mathrm{O}\right)\right]$, where DTPA-BMA is 1,7bis[( $N$-ethylcarbonyl)methyl]-1,4,7-triazaheptane-1,4,7-triacetic acid), was purchased from Amersham Health (Buckinghamshire, UK). Magnevist $\left(\left[\operatorname{Gd}(\mathrm{DTPA})\left(\mathrm{H}_{2} \mathrm{O}\right)\right]^{2-}\right)$ was prepared by mixing equimolar amounts of $\mathrm{Gd}\left(\mathrm{ClO}_{4}\right)_{3}$ and DTPA (diethylenetriamine- $N, N, N^{\prime}, N^{\prime \prime}, N^{\prime \prime}$-pentaacetic acid; Fluka); the absence of free metal ions was verified by performing a xylenol orange test at $\mathrm{pH}$ around 6 [18]. $\left[\mathrm{Gd}(\mathrm{DOTP})\left(\mathrm{H}_{2} \mathrm{O}\right)_{2.75}\right]^{5-}(\mathrm{Gd}(\mathrm{III})-(1,4,7,10$-tetraazacyclododecane-1,4,7,10-tetra(methylenephosphonate))) was purchased from Macrocyclics (Dallas, TX). All experiments were performed on an actively shielded 9.4-T, 31-cm bore Varian spectrometer with high-performance gradients (400 mT/m in $130 \mu \mathrm{s})$. A homebuilt surface coil consisting of two ${ }^{1} \mathrm{H}$ coils (operating in quadrature, $14 \mathrm{~mm}$ diameter) with a double-turn, 10-mm inner ${ }^{13} \mathrm{C}$ coil was used for both excitation and detection [19]. An equivalent surface coil with the inner coil tuned to ${ }^{6} \mathrm{Li}$ was constructed for the lithium-6 measurements. FASTMAP [20] was used for shimming.

All signals were measured as the peak integrals obtained from an inversion recovery sequence (predelay- $180_{x}-\tau-$ $90_{x}$ ). A hyperbolic secant $180^{\circ} \mathrm{RF}$ pulse [21] was used for inversion, while an adiabatic half-passage $90^{\circ}$ pulse [22] was used for excitation, which was immediately followed by acquisition of the FID. The inversion time $\tau$ was varied logarithmically from 0.01 to $40 \mathrm{~s}$ for ${ }^{13} \mathrm{C}$ and from 0.01 to $400 \mathrm{~s}$ for ${ }^{6} \mathrm{Li}$. To minimize experimental times, we omitted several long or short inversion times if the $T_{1}$ was estimated to be short or long, respectively. The resulting curve was

Table 1

Overview of the determined contrast agent relaxivities by resonance

\begin{tabular}{llcc}
\hline Substance & Contrast agent & $r_{1}\left(\mathrm{mM}^{-1} \mathrm{~s}^{-1}\right)$ & $R_{1, \text { dia }}\left(\mathrm{s}^{-1}\right)$ \\
\hline Formic acid & Omniscan & $2.88 \pm 0.05$ & $0.156 \pm 0.005$ \\
Glutamate $\mathrm{C} 1$ & Omniscan & $0.42 \pm 0.08$ & $0.10 \pm 0.02$ \\
Glutamate C5 & Omniscan & $0.55 \pm 0.10$ & $0.10 \pm 0.02$ \\
${ }^{6} \mathrm{Li}$ in $\mathrm{D}_{2} \mathrm{O}$ & Omniscan & $0.10 \pm 0.01$ & .9996 \\
${ }^{6} \mathrm{Li}$ in $\mathrm{H}_{2} \mathrm{O}$ & Omniscan & $0.091 \pm 0.007$ & .096 \\
${ }^{6} \mathrm{Li}$ in $\mathrm{H}_{2} \mathrm{O}$ & Magnevist & $0.33 \pm 0.03$ & $0.014 \pm 0.002$ \\
${ }^{6} \mathrm{Li}$ in $\mathrm{H}_{2} \mathrm{O}$ & Gd-DOTP & $11 \pm 1$ & $0.006 \pm 0.002$ \\
\hline
\end{tabular}

The fitted equation is $R_{1}=R_{1, \text { dia }}+r_{1}[\mathrm{CA}]$, where $R_{1, \text { dia }}$ is the diamagnetic relaxation rate or relaxation rate without contrast agent present . Errors are standard deviations from the fits. 


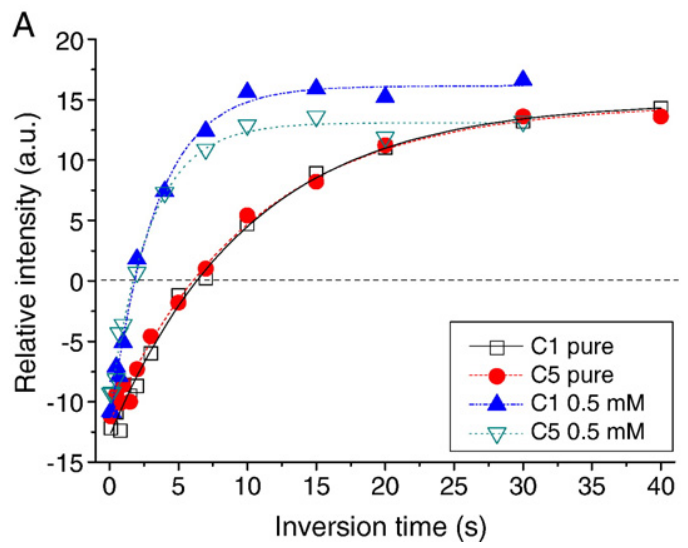

B

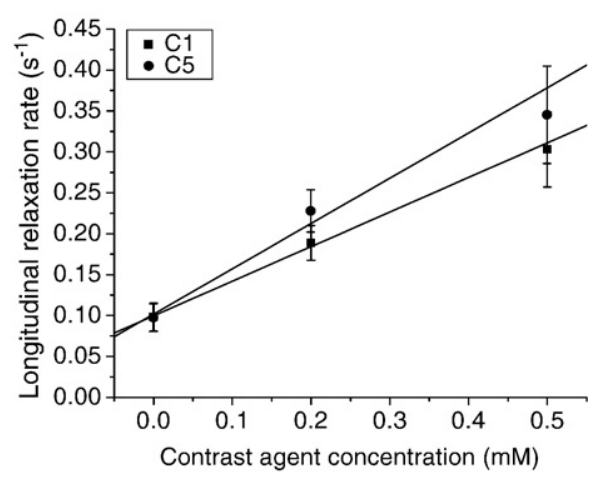

Fig. 2. Effect of Omniscan on the glutamate carboxyl carbon $T_{1}$. (A) Inversion recovery curves of the glutamate carboxyl carbons at different concentrations of Omniscan. (B) A linear fit of the relaxation rate $R_{1}\left(\mathrm{~s}^{-1}\right)$ versus the concentration of Omniscan $(\mathrm{mM})$ to determine the relaxivity of the carbons of the carboxyl groups of glutamate. Error bars represent the standard deviation on the inversion recovery fit.

fitted with $I=I_{0}\left(1-\alpha \cdot \exp \left(-\tau / T_{1}\right)\right)$ to determine $T_{1}$. The relaxivity $r_{1}$ was then calculated from the slope of a linear regression of $R_{1}\left(=1 / T_{1}\right)$ against the concentration of the contrast agent.

Omniscan was dissolved in $99 \%$ pure natural abundance formic acid at concentrations of $0,0.05,0.1,0.2$ and $0.5 \mathrm{mM}$. Omniscan was chosen as a relaxation agent because of its neutral charge as well as being less prone to complexation. The signal was averaged 16 times, and the relaxation delay was set to $25 \mathrm{~s}$.

Natural abundance glutamate $(1 \mathrm{M})$ was dissolved in phosphate-buffered saline at physiological $\mathrm{pH}$. Omniscan concentrations of $0,0.2$ and $0.5 \mathrm{mM}$ were added. The predelay was $25 \mathrm{~s}$, and the signal was averaged 32 times.

One hundred fifty millimolars of $\mathrm{LiCl}\left({ }^{6} \mathrm{Li}\right.$ is $7.4 \%$ naturally abundant) was dissolved in both $\mathrm{H}_{2} \mathrm{O}$ and $\mathrm{D}_{2} \mathrm{O}$. Magnevist $(0.05,0.1$ and $1 \mathrm{mM})$ was added to $\mathrm{H}_{2} \mathrm{O}$.
Omniscan was added to a separate $\mathrm{LiCl} / \mathrm{H}_{2} \mathrm{O}$ solution at 0.4 , 0.8 and $1.2 \mathrm{mM}$ and to the $\mathrm{D}_{2} \mathrm{O}$ solution at $0.1,0.2$ and $1 \mathrm{mM}$. Lastly, 5, 10 and $20 \mu \mathrm{M}$ Gd-DOTP was added to a third $\mathrm{LiCl} / \mathrm{H}_{2} \mathrm{O}$ solution to demonstrate the influence of the contrast agent charge on ${ }^{6} \mathrm{Li}$ relaxivity. The signal was averaged 16 times. The predelay was $150 \mathrm{~s}$ for contrast agent concentrations up to $0.8 \mathrm{mM}$, while a predelay of $25 \mathrm{~s}$ was used for the higher concentrations.

\section{Results}

When the concentration of Omniscan was increased up to $1 \mathrm{mM}$, a substantial effect on the line width of ${ }^{13} \mathrm{C}$ formic acid was not detected, although a profound effect on the inversion recovery signal was clearly discernible (Fig. 1A). At $0.5 \mathrm{mM}$ Omniscan, the relaxation rate $R_{1}$ of formic acid was increased by an order of magnitude from 0.15 to $1.54 \mathrm{~s}^{-1}$ (Fig. 1B).
A

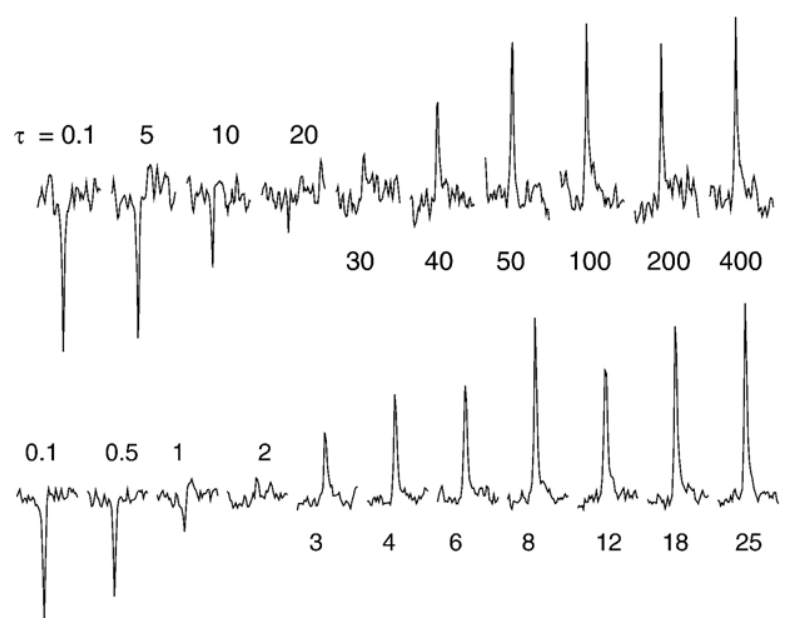

B

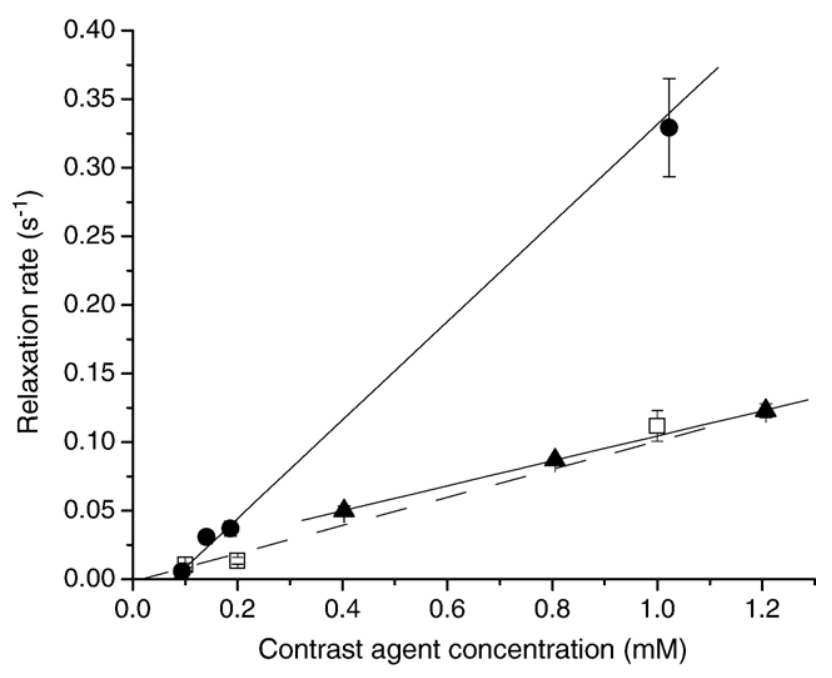

Fig. 3. The effect of contrast agents on lithium-6 transverse relaxation times. (A) Series of inversion recovery spectra for a $\mathrm{LiCl}$ solution in $\mathrm{H}_{2} \mathrm{O}$ with $0.05 \mathrm{mM}$ (upper panel) and $1 \mathrm{mM}$ (lower panel) of Omniscan. Inversion times are mentioned for each individual spectrum. (B) Determination of the relaxivity for the Magnevist in $\mathrm{H}_{2} \mathrm{O}(\bullet)$, Omniscan in $\mathrm{H}_{2} \mathrm{O}(\boldsymbol{\Delta})$ and Omniscan in $\mathrm{D}_{2} \mathrm{O}(\square)$ solutions. Error bars represent standard deviations of the inversion recovery curve fits. 
Consequently, the relaxivity $r_{1}$ of Omniscan in formic acid was $\sim 3 \mathrm{mM}^{-1} \mathrm{~s}^{-1}$ (Table 1, row 1), roughly two thirds of its proton relaxivity, which has been reported to be on the order of $4.5 \mathrm{mM}^{-1} \mathrm{~s}^{-1}$ at comparable field strengths [7].

The $T_{1}$ of the glutamate carboxyl resonances $\mathrm{C} 1$ and $\mathrm{C} 5$ without contrast agents added was within experimental error identical and on the order of $10 \mathrm{~s}$ as judged from the inversion recovery signal (Fig. $2 \mathrm{~A}$ ); that is, $T_{1, \mathrm{C} 1}=10.2 \pm 0.8$ $\mathrm{s}$ and $T_{1, \mathrm{C} 5}=10.3 \pm 0.8 \mathrm{~s}$. After adding Omniscan at 0.2 and $0.5 \mathrm{mM}, T_{1}$ was shortened to about 5 and $3 \mathrm{~s}$, respectively, resulting in similar relaxivities of $\sim 0.50 \mathrm{mM}^{-1} \mathrm{~s}^{-1}$ (Fig. 2B and Table 1, rows 2 and 3 ).

The longitudinal relaxation time of ${ }^{6} \mathrm{Li}$ was substantially longer, even in the presence of Omniscan (Fig. 3). For Omniscan, the derived relaxivities in both $\mathrm{H}_{2} \mathrm{O}$ and $\mathrm{D}_{2} \mathrm{O}$ were on the order of $0.1 \mathrm{mM}^{-1} \mathrm{~s}^{-1}$ (rows 4 and 5 in Table 1). Since the standard deviation values of the $T_{1}$ measurements scale with relative value, it decreased with relaxation time. When using Magnevist, a threefold higher relaxivity of $\sim 0.3 \mathrm{mM}^{-1} \mathrm{~s}^{-1}$ was obtained (row 6 in Table 1). The effect of contrast agents on nuclei in charged particles is expected to be different depending on the charge of the contrast agent; we therefore measured the relaxivity of the highly charged Gd-DOTP on ${ }^{6} \mathrm{Li}$, which was two orders of magnitude higher than that of Omniscan (last row in Table 1).

\section{Discussion}

The present study reports the relaxivities of several contrast agents on two nonproton nuclei with intrinsically long relaxation times, namely, ${ }^{13} \mathrm{C}$ and ${ }^{6} \mathrm{Li}$. Although the effect of commercially available contrast agents varied by two orders of magnitude, substantial $T_{1}$ shortening can be accomplished in vitro, and thus, experimental measurement times can be shortened, such as those for ${ }^{13} \mathrm{C}$ NMR calibrations using formic acid signal in an external reference. Despite the fact that, under the acidic conditions of pure formic acid solutions, Gd(III) is free and most likely not complexed with the ligand, $r_{1}$ is lower than that observed for water ${ }^{1} \mathrm{H}\left(\sim 4 \mathrm{mM}^{-1} \mathrm{~s}^{-1}\right)$. One possible explanation might be that the ${ }^{13} \mathrm{C}$ nucleus in formic acid primarily experiences second and/or outer-sphere relaxation; this is possible due to the fact that the attached atoms hinder it from reaching the inner sphere of the contrast agent complex. On the other hand, the relaxivity is also expected to be reduced compared to protons due to the fourfold lower nuclear gyromagnetic ratio, which affects relaxivity in an almost quadratic fashion according to the Solomon-Bloembergen-Morgan equations [7,8].

The relaxivity being lower for glutamate at physiological $\mathrm{pH}$ than for formic acid at low $\mathrm{pH}$ was explained by the presence of the complex around the $\mathrm{Gd}^{3+}$ ion. According to the structure of Magnevist (which has one hydration site), one can directly exclude any inner-sphere coordination of glutamate to the paramagnetic center due to steric hindrance around the bound water molecule. The replacement of a water molecule in the first coordination sphere is, however, a common phenomenon that is well established for the proton relaxivity of some bishydrated chelates like $\left[\mathrm{Gd}(\mathrm{DO} 3 \mathrm{~A})\left(\mathrm{H}_{2} \mathrm{O}\right)_{2}\right]$ by small organic molecules such as lactate, malonate, citrate [23-25] or proteins [26]. For Magnevist, the absence of coordination of glutamate ${ }^{13} \mathrm{C}$ to the inner sphere of the paramagnetic center induces an increase of the distance between the nuclei of interest and the Gd(III), thus resulting in a lower relaxivity.

Despite the fact that inner-sphere effects are less dominant and that the reduced gyromagnetic ratio further hampers the relaxivity, a concentration of $2 \mathrm{mM}$ of Omniscan is predicted to shorten $T_{1}$ of glutamate carboxyl carbons to $\sim 1 \mathrm{~s}$, which can be exploited with an increased repetition rate to achieve an approximately threefold sensitivity gain. Preliminary measurement of brain extract obtained from a rat infused with $1-{ }^{13} \mathrm{C}$ glucose for several hours indicated that a repetition time of $3 \mathrm{~s}$ was close to full relaxation for the carboxyl resonances of glutamate (data not shown).

The aforementioned experiments demonstrate that the longitudinal relaxation rate can be increased in a predictive fashion using Gd-based contrast agents. Although the relaxivity was weaker as compared with water protons, it has a substantial effect that can be exploited to increase the sensitivity in vitro for measuring carboxyl resonances. Contrast agents, thus, can be used in carbon spectroscopy studies on slowly relaxing resonances such as carboxyl groups to gain substantial time and sensitivity. The calculated $r_{1}$ suggests that the $T_{1}$ of glutamate carboxyl carbons can effectively be reduced from 10 to $\sim 1 \mathrm{~s}$ at an Omniscan concentration of $2 \mathrm{mM}$.

The three different contrast agents resulted in ${ }^{6} \mathrm{Li}$ relaxivities that spanned two orders of magnitude, which was attributed to the charge of the contrast agent chelate: at physiological $\mathrm{pH}$, Omniscan is neutral and, thus, will not strongly interact with the ${ }^{6} \mathrm{Li}$ ion's positive charge. Therefore, contrast agents with a different charge were expected to have a different relaxivity. Magnevist is negatively charged (a net charge of -2 at neutral $\mathrm{pH}$ ) and indeed had a threefold higher relaxivity than Omniscan, whereas Gd-DOTP had a hundredfold higher relaxivity than Omniscan. This can be explained with the net charge of -5 and the presence of four coordination sites for positively charged ions, reducing effectively the distance between the ${ }^{6} \mathrm{Li}$ and the $\mathrm{Gd}^{3+}$ center [27]. Overall, these experiments indicate that with suitable contrast agents tailored to the nucleus studied (or even compound), potent relaxivities can potentially be achieved. When taking into account that the relaxivity is approximately proportional to the square of the gyromagnetic ratio of the nucleus (for ${ }^{6} \mathrm{Li}$, this is $\sim 2 \%$ of protons) and to $S(S+1)$ (2.7-fold of protons), a "proton relaxivity equivalent" can be calculated, which was $2 \mathrm{mM}^{-1} \mathrm{~s}^{-1}$, about in the same order of magnitude of Magnevist in water. The high relaxivity of DOTP, on the 
other hand, would result in a proton relaxivity equivalent of 185; DOTP, thus, is clearly a very potent contrast agent.

Aside from the obvious sensitivity gains, the long intrinsic relaxation times of $\mathrm{X}$ nuclei offer the prospective of detecting contrast agents at very low concentrations. For example, when assuming that, at $10 \mathrm{~s}$, a signal reduction by $10 \%$ in a ${ }^{13} \mathrm{C}$ is detectable, from solving

$$
\frac{\exp \left[-\mathrm{TR}\left(R_{1 \mathrm{dia}}+[\mathrm{CA}] r_{1}\right)\right]}{\exp \left[-\mathrm{TR} R_{1 \mathrm{dia}}\right]}=\exp \left(-\mathrm{TR}[\mathrm{CA}] r_{1}\right)=0.9,
$$

the presence of $[\mathrm{CA}] \sim 20 \mu \mathrm{M}$ should be detectable with a relaxivity of $0.5 \mathrm{mM}^{-1} \mathrm{~s}^{-1}$. Likewise, assuming that a $10 \%$ decrease in signal is detectable at $100 \mathrm{~s}$ (on the order of $T_{1}$ of ${ }^{6} \mathrm{Li}$ in $\mathrm{H}_{2} \mathrm{O}$ ), the presence of $\sim 100 \mathrm{nM}$ of Gd-DOTP should be discernible. Given the recent advent of hyperpolarized ${ }^{13} \mathrm{C}$ for in vivo imaging [28], it is realistic to consider the potential detection of contrast agents at concentrations well below what is currently being used given that such contrast agents can be custom synthesized with favorable properties for the nucleus and/or compound to be studied.

We conclude that the determined ${ }^{13} \mathrm{C}$ and ${ }^{6} \mathrm{Li}$ relaxivity of commercially available contrast agents is strong enough to allow the preparation of solutions with a predetermined and well-defined relaxation enhancement, which offers significant sensitivity enhancement and the perspective of detecting contrast agents at potentially very low concentrations.

\section{Acknowledgments}

The authors would like to thank Prof. Navon for pointing out the long relaxation times of ${ }^{6} \mathrm{Li}$. This study was supported by Centre d'Imagerie BioMédicale (CIBM) of the UNIL, UNIGE, HUG, CHUV, EPFL and by the Leenaards and Jeantet Foundations, as well as by NIH Grant R01NS42005.

\section{References}

[1] Gruetter R, Seaquist ER, Ugurbil K. A mathematical model of compartmentalized neurotransmitter metabolism in the human brain. Am J Physiol Endocrinol Metab 2001;281(1):E100-12.

[2] Gruetter R. In vivo 13C NMR studies of compartmentalized cerebral carbohydrate metabolism. Neurochem Int 2002;41(2-3):143-54.

[3] Cerdan S, Kunnecke B, Seelig J. Cerebral metabolism of [1,2$13 \mathrm{C} 2$ ]acetate as detected by in vivo and in vitro $13 \mathrm{C}$ NMR. J Biol Chem 1990;265(22):12916-26.

[4] Lettvin J, Sherry AD. Gd(TTHA): an aqueous carbon-13 relaxation reagent. J Magn Reson 1977;28:459-61.

[5] Gruetter R, Adriany G, Merkle H, Andersen PM. Broadband decoupled, $1 \mathrm{H}$-localized 13C MRS of the human brain at 4 tesla. Magn Reson Med 1996;36(5):659-64.

[6] Choi IY, Tkac I, Gruetter R. Single-shot, three-dimensional "nonecho" localization method for in vivo NMR spectroscopy. Magn Reson Med 2000;44(3):387-94.

[7] Caravan P, Ellison JJ, McMurry TJ, Lauffer RB. Gadolinium(III) chelates as MRI contrast agents: structure, dynamics, and applications. Chem Rev 1999;99(9):2293-352.
[8] Merbach A, Tóth É.. The chemistry of contrast agents in medical magnetic resonance imaging. New York: Wiley; 2001.

[9] Traboulsee AL, Li DK. The role of MRI in the diagnosis of multiple sclerosis. Adv Neurol 2006;98:125-46.

[10] Trattnig S, Ba-Ssalamah A, Noebauer-Huhmann IM, Barth M, Wolfsberger S, Pinker K, et al. MR contrast agent at high-field MRI (3 tesla). Top Magn Reson Imaging 2003;14(5):365-75.

[11] Aime S, Barge A, Cabella C, Crich SG, Gianolio E. Targeting cells with MR imaging probes based on paramagnetic Gd(III) chelates. Curr Pharm Biotechnol 2004;5(6):509-18.

[12] Terreno E, Botta M, Dastrù W, Aime S. Gd-enhanced MR images of substrates other than water. Contr Med Mol Imaging 2006;1:101-5.

[13] Gruetter R, Adriany G, Choi IY, Henry PG, Lei H, Oz G. Localized in vivo 13C NMR spectroscopy of the brain. NMR Biomed 2003;16(6-7): 313-38.

[14] van Heeswijk RB, Duarte JMN, Laus S, Gruetter R. Usage of paramagnetic contrast agents to enhance $13 \mathrm{C}$ signal detection in vitro. Book of abstracts: Fourteenth Annual Meeting of the International Society for Magnetic Resonance in Medicine Seattle, WA: ISMRM. 2006. p. 492.

[15] Villafranca JJ, Raushel FM. Biophysical applications of NMR to phosphoryl transfer enzymes and metal nuclei of metalloproteins. Annu Rev Biophys Bioeng 1980;9:363-92.

[16] Wehrli F. Temperature-dependent spin-lattice relaxation of $6 \mathrm{Li}$ in aqueous lithium chloride. J Magn Reson 1976;23:527-32.

[17] Compton MT, Nemeroff CB. The treatment of bipolar depression. J Clin Psych 2000;61(Suppl 9):57-67.

[18] Brunisholz G, Randin M. Sur la séparation des terres rares à l'aide de l'acide éthylènediamine-tétraacétique. IX. Procédé en cycle pour le fractionnement des terres yttriques. Helv Chim Acta 1959;42(6):1927-38.

[19] Adriany G, Gruetter R. A half-volume coil for efficient proton decoupling in humans at 4 tesla. J Magn Reson 1997;125(1):178-84.

[20] Gruetter R. Automatic, localized in vivo adjustment of all first- and second-order shim coils. Magn Reson Med 1993;29(6):804-11.

[21] Tannus A, Garwood M. Improved performance of frequency-swept pulses using offset-independent adiabaticity. J Magn Reson A 1996;120(1):133-7.

[22] Garwood M, DelaBarre L. The return of the frequency sweep: designing adiabatic pulses for contemporary NMR. J Magn Reson 2001;153(2):155-77.

[23] Botta M, Aime S, Barge A, Bobba G, Dickins RS, Parker D, et al. Ternary complexes between cationic Gd-III chelates and anionic metabolites in aqueous solution: an NMR relaxometric study. Chem Eur J 2003;9(9):2102-9.

[24] Aime S, Botta M, Bruce JI, Mainero V, Parker D, Terreno E. Modulation of the water exchange rates in [Gd-DO3A] complex by formation of ternary complexes with carboxylate ligands. Chem Commun 2001;(01):115-6.

[25] Bruce JI, Dickins RS, Govenlock LJ, Gunnlaugsson T, Lopinski S, Lowe MP, et al. The selectivity of reversible oxy-anion binding in aqueous solution at a chiral europium and terbium center: signaling of carbonate chelation by changes in the form and circular polarization of luminescence emission. J Am Chem Soc 2000;122(40): 9674-84.

[26] Aime S, Gianolio E, Terreno E, Giovenzana GB, Pagliarin R, Sisti M, et al. Ternary Gd(III)L-HSA adducts: evidence for the replacement of inner-sphere water molecules by coordinating groups of the protein. Implications for the design of contrast agents for MRI. J Biol Inorg Chem 2000;5(4):488-97.

[27] Avecilla F, Peters JA, Geraldes CFGC. X-ray crystal structure of a sodium salt of $[\mathrm{Gd}(\mathrm{DOTP})](5-)$ : implications for its second-sphere relaxivity and the Na-23 NMR hyperfine shift effects of [Tm(DOTP)](5-). Eur J Inorg Chem 2003;(23):4179-86.

[28] Golman K, Axelsson O, Johannesson H, Mansson S, Olofsson C, Petersson JS. Parahydrogen-induced polarization in imaging: subsecond (13)C angiography. Magn Reson Med 2001;46(1):1-5. 